Article

\title{
Biochars Derived from Gasified Feedstocks Increase the Growth and Improve Nutrient Acquisition of Triticum aestivum (L.) Grown in Agricultural Alfisols
}

\author{
Kristin M. Trippe *, Stephen M. Griffith, Gary M. Banowetz and Gerald W. Whitaker \\ US Department of Agriculture Agricultural Research Service National Forage Seed and Production \\ Research Center, Corvallis, OR 97331, USA; E-Mails: smgriffith@me.com (S.M.G.); \\ banowetg@gmail.com (G.M.B.); Jerry.Whittaker@ars.usda.gov (G.W.W.) \\ * Author to whom correspondence should be addressed; E-Mail: Kristin.Trippe@ARS.USDA.GOV; \\ Tel.: +1-541-738-4181.
}

Academic Editor: Bin Gao

Received: 18 June 2015 / Accepted: 12 August 2015 / Published: 19 August 2015

\begin{abstract}
Biochars are produced by low-oxygen gasification or pyrolysis of organic waste products, and can be co-produced with energy, achieving waste diversion and delivering a soil amendment that can improve agricultural yields. Although many studies have reported the agronomic benefits of biochars produced from pyrolysis, few have interrogated the ability of gasified biochars to improve crop productivity. An earlier study described the ability of a biochar that was derived from gasified Kentucky bluegrass (KB) seed screenings to impact the chemistry of acidic agricultural soils. However, that study did not measure the effects of the biochar amendment on plant growth or on nutrient acquisition. To quantify these effects we conducted a greenhouse study that evaluated wheat grown in agricultural soils amended with either the KB-based biochar or a biochar derived from a blend of woody mixed-waste. Our studies indicated that biochar amended soils promoted the growth of wheat in these agricultural alfisols. Our elemental analysis indicated that an attenuation of metal toxicity was likely responsible for the increased plant growth. The results of our study are placed in the context of our previous studies that characterized KBsourced biochar and its effects on soil chemistry.
\end{abstract}

Keywords: Triticum aestivum L.; gasification; biochar; seed screenings; wheat; nutrition; acid soil; Kentucky bluegrass; aluminum toxicity 


\section{Introduction}

The thermo conversion of crop residues has the potential to generate value-added agricultural income from the production of on-farm energy, the capture of process heat, and biochar production [1,2]. Biochar, a highly-persistent form of organic matter, has demonstrated agronomic benefits [3]. However, the agricultural benefits of biochar are difficult to predict because highly variable production methods often result in radically different physiochemical properties, which in turn impact the ability of a biochar to amend soil conditions [4]. Although this complexity has led to a proliferation of biochar characterization studies, generalizable principles and agronomic recommendations have been slow to emerge.

Thermo conversion of crop residues occurs either by pyrolysis, an anerobic combustion process that occurs at temperatures below $700{ }^{\circ} \mathrm{C}$, or gasification, a process that occurs in the presence of controlled oxygen concentrations at higher temperatures [5]. The vast majority of studies that interrogate the physiochemical characteristics and utility of biochars are focused on those produced by pyrolysis, and most studies that characterize biochar generated by gasification are focused on woody source material. Studies that use gasified herbaceous feedstocks have looked at the effects of biochar on soil fertility [6], plant germination [7], and plant growth [8]. However, because studies regarding the effect of gasified herbaceous source materials on plants and soils have only occasionally been reported, and because gasified biochar has a strong effect on soils [4], we were interested in determining the effect of gasified herbaceous source material on plant nutritional status.

Recently our research has been focused on the ability of a farm-scale gasifier to produce bioenergy [9], and biochar [10] from the seed screenings and residual straw [1] from perennial grasses. We previously described the physiochemical properties of the biochar produced from the gasified seed screenings of Kentucky bluegrass (KB) [10]. The KB biochar possessed similar physical and chemical characteristics to biochars sourced from alfalfa stems [11] and other gasified herbaceous feedstocks, including a high ash content, moderate alkalinity, and the absence of detectible metals or PAHs. The impact of KB biochar on the chemistry of agricultural soils was recently described [12]. However, that study did not measure the effects of the biochar amendment on plant growth or on nutrient acquisition. Because the KB biochar was similar to that produced from alfalfa, we hypothesized that the application of this biochar to agricultural soils might evoke a similar plant response. The objectives of this study were to evaluate the effects of two types of biochar amendments on the growth and nutritional status of wheat and to compare different application rates of biochar.

To achieve these objectives, we conducted a replicated greenhouse study that used two agricultural soils, each amended with either the KB-based biochar or a biochar derived from a blend of woody mixed-waste. Our studies indicated that the addition of either herbaceous or woody biochar significantly increased the ability of wheat to grow in these highly acidic and weathered soils. Our analyses indicated that the mechanism for increased plant growth was most likely an attenuation of metal toxicity and an increase in soil fertility provided by increased $\mathrm{pH}$, absorbtion of soil metals onto biochar particles, and increased soil nutrient content. 


\section{Results}

\subsection{Plant Growth}

The above-ground and below-ground biomass of wheat plants increased when either soil series was amended with either biochar (Figure 1). However, this increase was only sometimes significant (Table 1). In the shoots, the increase in the dry weight was proportional to the biochar amendment rate for each biochar $(p \leq 0.05)$. However, wood-sourced biochar amendments out performed KB-biochars in their ability to increase shoot mass. In the roots, wood-sourced char also out performed KB-biochars in their ability to increase biomass. However, this effect was not as pronounced as it was in the above-ground biomass, and was more dramatic in the Bernhill soil series, where root growth was initially limited. Biochar sourced from KB seed screenings did not impact root growth in either soil series. Our collective results indicate that $\mathrm{KB}$-sourced biochar specifically impacted the growth of shoots while wood-sourced biochar had broader impacts on the growth, increasing the growth of both the shoot and the root.

The elemental composition of roots and shoots was altered when soils were amended with biochar (Figures 2-8), however these results were not consistent across soil series or biochar sources. For example, in the shoots we observed that the concentration of Al (Figure 2A) decreased as biochar concentrations increased, however this result was not statistically significant. In the roots, the accumulation of $\mathrm{Al}$ decreased when either soil series was amended with either biochar, however, the impact of KB-sourced biochar (Figure 2B) on $\mathrm{Al}$ accumulation in the root was more pronounced and statistically relevant.

In general, the effect of biochar source on elemental composition of plant roots was more specific than in plant shoots. In plant roots, both $\mathrm{KB}$ - and wood-sourced biochars reduced the accumulation of $\mathrm{Na}$ (Figure 3B), but increased the accumulation of $\mathrm{K}$ (Figure 4B) and Mg (Figure 5B). The roots of plants grown in soils amended with KB biochars accumulated less Fe (Supplementary Table S1), Mn (Supplementary Table S1), and Ni (Figure 6B), but accumulated more P (Figure 7B). Wood-sourced biochar amendments reduced the accumulation of $\mathrm{S}$ and $\mathrm{Cu}$ (Supplementary Table S1), but facilitated root accumulation of $\mathrm{Ca}$ (Figure 8B).

The effects of the biochar amendments in plant shoots were not as sensitive to the biochar source material as the roots. Plants grown in soils amended with either biochar accumulated more $\mathrm{K}$ (Figure 4A), Mg (Figure 5A), and $\mathrm{P}$ (Figure 7A) but accumulated less Ni (Figure 6A) and $\mathrm{Ca}$ (Figure 8A) in their shoots. Wood-sourced biochar amendments reduced shoot accumulation of $\mathrm{S}$ (Supplementary Table S2).

The elemental concentration of roots was not necessarily a reflection of soil concentrations. For example, Ca concentrations increased in soils, but decreased in shoots. Likewise, Na (Figure 3B), $\mathrm{Mg}$ (Figure 5b), Fe (Supplementary Table S3), and Ni (Figure 6B) concentrations in the soil remained constant, but concentrations in the roots or shoots decreased. However, the concentration of $\mathrm{P}$ and $\mathrm{K}$ in amended soils correlated nicely with the increase in roots and shoots. 
Table 1. The elemental compositions of the root and shoot $(\mathrm{mg} / \mathrm{kg})$ were statistically analyzed using the General Linear Model $(\mathrm{A}+\mathrm{B}+\mathrm{C}+\mathrm{D}+\mathrm{BC}+\mathrm{BD}+\mathrm{CD}+\mathrm{BCD})$ that included planned comparisons testing whether the linear and quadratic components were significant. The asterisk indicates estimates that are statistically significant $(p \leq 0.05)$.

\begin{tabular}{|c|c|c|c|c|c|c|c|c|c|c|c|c|c|c|c|}
\hline \multirow[t]{2}{*}{$\mathbf{u}$} & \multicolumn{2}{|c|}{ Biochar Type } & \multicolumn{2}{|c|}{ Soil Type } & \multicolumn{2}{|c|}{$\begin{array}{c}\text { KB Biochar } \\
\text { Concentration }\end{array}$} & \multicolumn{2}{|c|}{$\begin{array}{l}\text { Wood Biochar } \\
\text { Concentration }\end{array}$} & \multicolumn{2}{|c|}{$\begin{array}{c}\text { Biochar Type } \times \text { Soil } \\
\text { Source }\end{array}$} & \multicolumn{2}{|c|}{$\begin{array}{c}\text { Soil Type } \times \text { KB } \\
\text { Biochar } \\
\text { Concentration }\end{array}$} & \multicolumn{2}{|c|}{$\begin{array}{c}\text { Soil Type } \times \text { Wood } \\
\text { Biochar } \\
\text { Concentration } \\
\end{array}$} & \multirow[b]{2}{*}{$\operatorname{Adj} R^{2}$} \\
\hline & Estimate & S. E. & Estimate & S. E. & Estimate & S. E. & Estimate & S. E. & Estimate & S. E. & Estimate & S. E. & Estimate & S. E. & \\
\hline Root mass & -0.037 & 0.049 & $0.361 *$ & 0.049 & 1.213 & 0.84 & $5.02 *$ & 0.84 & -0.137 & 0.069 & -0.955 & 1.188 & 0.689 & 1.188 & 0.7 \\
\hline Shoot mass & 0.00 & 0.074 & $0.436 *$ & 0.074 & $4.80 *$ & 1.28 & $7.21 *$ & 1.28 & -0.053 & 0.105 & 1.07 & 1.81 & $10.8 *$ & 1.81 & 0.85 \\
\hline Root Al & $-430 *$ & 131 & 141 & 131 & $-9411 *$ & 2248 & -3950 & 2248 & 136 & 185 & -3554 & 3179 & -5337 & 3179 & 0.44 \\
\hline Root $\mathrm{Ca}$ & $288 *$ & 67 & 50.4 & 67.1 & 1272 & 1150 & $6495 *$ & 1150 & -84.7 & 94.9 & -651 & 1627 & $-5532 *$ & 1627 & 0.6 \\
\hline Root Fe & $-315 *$ & 104 & $258 *$ & 104 & $-4319 *$ & 1790 & 56.5 & 1790 & 169 & 148 & -4177 & 2531 & $-6798 *$ & 2531 & 0.36 \\
\hline Root $\mathrm{K}$ & $-2013 *$ & 672 & -340 & 672 & $39564 *$ & 11528 & $23358 *$ & 11528 & 287 & 950 & -12726 & 16303 & -22913 & 16303 & 0.44 \\
\hline Root Mg & $87.1 *$ & 36 & -36.4 & 36 & $3445 *$ & 617 & $4302 *$ & 617 & -50.3 & 50.8 & $-2226 *$ & 873 & $-3610 *$ & 873 & 0.64 \\
\hline Root $\mathrm{Na}$ & 106 & 111 & $-540 *$ & 111 & $-11172 *$ & 1904 & $-11498 *$ & 1904 & 121 & 157 & $7717 *$ & 2693 & 5137 & 2693 & 0.53 \\
\hline Root Ni & $4.211 *$ & -0.973 & $3.628 *$ & -0.973 & $-33.575 *$ & -16.683 & $-130 *$ & -16.683 & $-4.732 *$ & -1.376 & -28.125 & -23.6 & 30.515 & -23.593 & 0.589 \\
\hline Root P & -405 & 225 & $-1162 *$ & 225 & $22,119 *$ & 3854 & 501 & 3854 & 577 & 318 & -200 & 5451 & -8946 & 5451 & 0.69 \\
\hline Root $S$ & -134 & 92.9 & $-308 *$ & 92.9 & 963 & 1593 & $-5498 *$ & 1593 & -73.7 & 131 & $-4510 *$ & 2253 & $-5413 *$ & 2253 & 0.72 \\
\hline Root Zn & $22.3 *$ & 6.76 & $-45.7 *$ & 6.76 & -199 & 116 & $-750 *$ & 116 & -16.9 & 9.56 & 179 & 164 & $457 *$ & 164 & 0.7 \\
\hline Shoot Al & 20.1 & 28.5 & $101 *$ & 28.5 & -535 & 488 & -396 & 488 & -25.8 & 40.3 & 417 & 690 & -604 & 690 & 0.3 \\
\hline Shoot Ca & $-574 *$ & 240 & $-636 *$ & 240 & $-30,750 *$ & 4110 & $-22,400 *$ & 4110 & -51.5 & 339 & $14,040 *$ & 5813 & 9901 & 5813 & 0.56 \\
\hline Shoot Fe & 14.2 & 23.3 & $74.3 *$ & 23.3 & -285 & 400 & -15 & 400 & 2.76 & 32.9 & 366 & 565 & -726 & 565 & 0.28 \\
\hline Shoot K & $4180 *$ & 1010 & 584 & 1010 & $98,648 *$ & 17,322 & $74,325 *$ & 17,322 & -1967 & 1428 & $-38,238$ & 24498 & $-76,180 *$ & 24,498 & 0.5 \\
\hline Shoot Mg & 158 & 86.8 & $-349 *$ & 86.8 & $4311^{*}$ & 1488 & $6845 *$ & 1488 & -41.6 & 123 & 1159 & 2104 & -992 & 2104 & 0.6 \\
\hline Shoot $\mathrm{Na}$ & -2.06 & 22.9 & -27.4 & 22.9 & -148 & 393 & -21.2 & 393 & -13.3 & 32.4 & 201 & 556 & 80.5 & 556 & 0.03 \\
\hline Shoot Ni & $-0.8 *$ & -0.137 & $-0.522 *$ & -0.137 & $-16.733 *$ & -2.355 & -4.064 & -2.355 & $0.632 *$ & -0.194 & $11.908 *$ & -3.33 & -0.98 & -3.33 & 0.44 \\
\hline Shoot P & $628 *$ & 223 & $-622 *$ & 223 & $11664 *$ & 3825 & $14426 *$ & 3825 & -387 & 315 & 9446 & 5410 & -8150 & 5410 & 0.56 \\
\hline Shoot S & $849 *$ & 162 & $-788 *$ & 162 & 3639 & 2786 & $-14137 *$ & 2786 & $-735 *$ & 230 & -7475 & 3940 & 5278 & 3940 & 0.73 \\
\hline Shoot $\mathrm{Zn}$ & 3.14 & 3.24 & $-10.8 *$ & 3.25 & 18.2 & 55.7 & 44.6 & 55.7 & 2.58 & 4.59 & 120 & 78.8 & -20.3 & 78.8 & 0.23 \\
\hline
\end{tabular}




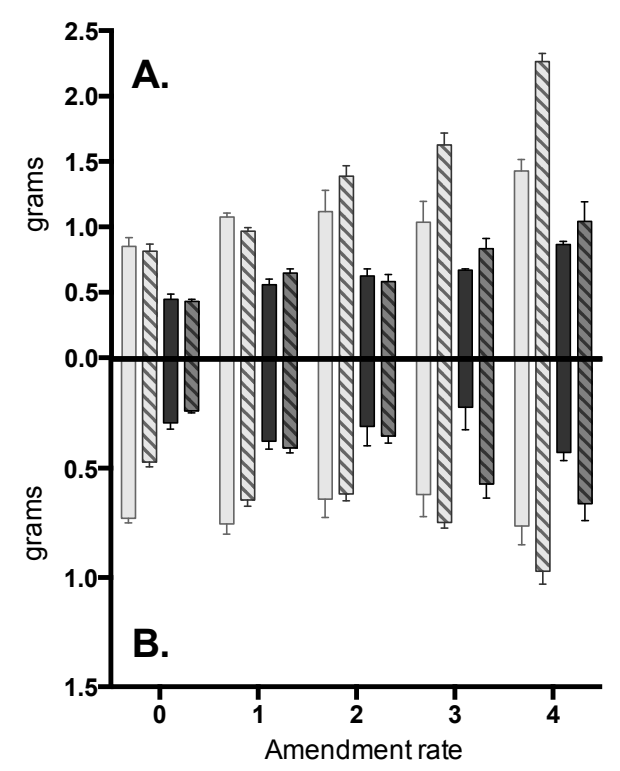

Figure 1. The dry mass of shoots $(\mathbf{A})$ and roots (B) grown in Freeman (light grey) or Bernhill (dark grey) soils amended with KB- (solid) or wood- (cross-hatched) sourced biochars. Amendment rates are represented as $0-4$, which correspond to rates of $0 \%, 3 \%$, $6 \%, 16 \%$, and $25 \%$ by volume for both biochars, $0 \%, 0.7 \%, 1.7 \%, 3.7 \%$, and $8.6 \%$ by mass for wood biochar, and $0 \%, 0.4 \%, 1.2 \%, 2.5 \%$, and $5.8 \%$ by mass for KB-sourced biochar.

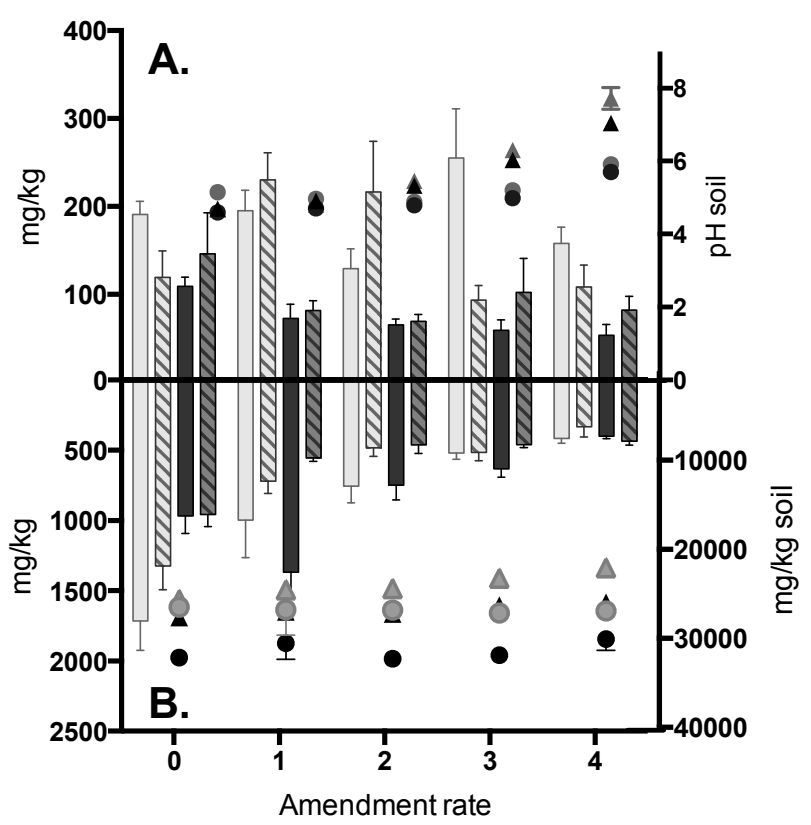

Figure 2. The aluminum concentration of shoots (A) and roots (B) grown in Freeman (light grey) or Bernhill (dark grey) soils amended with KB- (solid) or wood- (crosshatched) sourced biochars. The $\mathrm{pH}$ of the soils (right axis, (A)) and the soil aluminum concentration (right axis, (B)) is also plotted for Freeman (light grey) or Bernhill (dark grey) soils amended with KB- (circle) or wood- (triangle) sourced biochars (Trippe 2015). Amendment rates are represented as $0-4$, which correspond to rates of $0 \%, 3 \%, 6 \%, 16 \%$, and $25 \%$ by volume for both biochars, $0 \%, 0.7 \%, 1.7 \%, 3.7 \%$, and $8.6 \%$ by mass for wood biochar, and $0 \%, 0.4 \%, 1.2 \%, 2.5 \%$, and $5.8 \%$ by mass for KB-sourced biochar. 


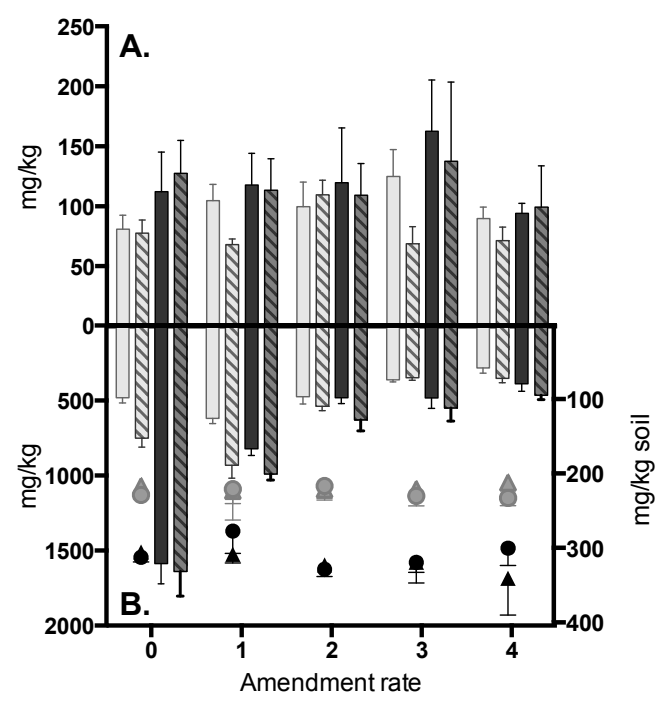

Figure 3. The sodium concentration of shoots (A) and roots (B) grown in Freeman (light grey) or Bernhill (dark grey) soils amended with KB- (solid) or wood- (crosshatched) sourced biochars. The sodium of the soils (right axis, (B)) is also plotted for Freeman (light grey) or Bernhill (dark grey) soils amended with KB- (circle) or wood- (triangle) sourced biochars. Amendment rates are represented as $0-4$, which correspond to rates of $0 \%, 3 \%, 6 \%, 16 \%$, and $25 \%$ by volume for both biochars, $0 \%, 0.7 \%$, $1.7 \%, 3.7 \%$, and $8.6 \%$ by mass for wood biochar, and $0 \%, 0.4 \%, 1.2 \%, 2.5 \%$, and $5.8 \%$ by mass for KB-sourced biochar.

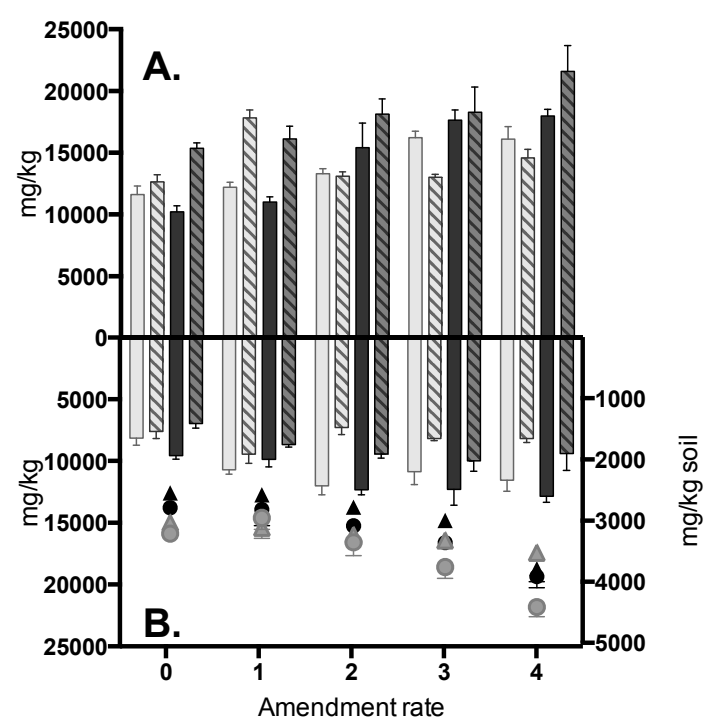

Figure 4. The potassium concentration of shoots (A) and roots (B) grown in Freeman (light grey) or Bernhill (dark grey) soils amended with KB- (solid) or wood- (crosshatched) sourced biochars. The potassium of the soils (right axis, (B)) is also plotted for Freeman (light grey) or Bernhill (dark grey) soils amended with KB- (circle) or wood- (triangle) sourced biochars (Trippe 2015). Amendment rates are represented as 0-4, which correspond to rates of $0 \%, 3 \%, 6 \%, 16 \%$, and $25 \%$ by volume for both biochars, $0 \%, 0.7 \%, 1.7 \%, 3.7 \%$, and $8.6 \%$ by mass for wood biochar, and $0 \%, 0.4 \%, 1.2 \%, 2.5 \%$, and $5.8 \%$ by mass for KB-sourced biochar. 


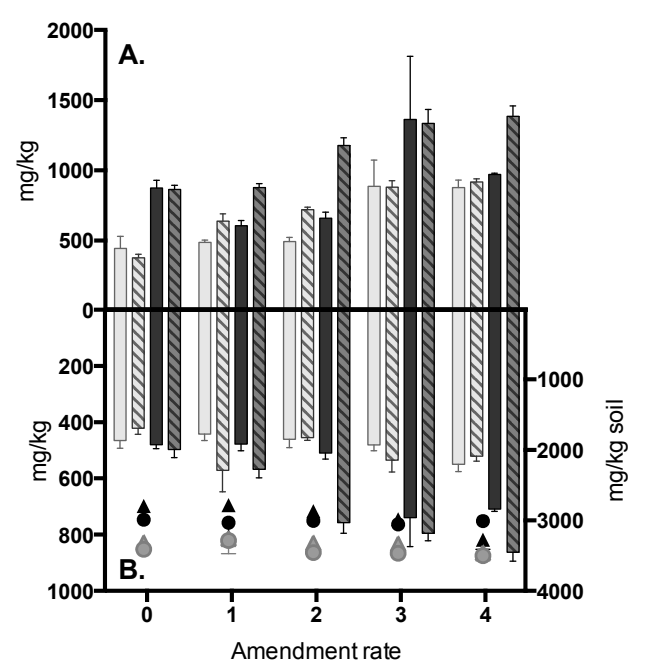

Figure 5. The magnesium concentration of shoots $(\mathbf{A})$ and roots $(\mathbf{B})$ grown in Freeman (light grey) or Bernhill (dark grey) soils amended with KB- (solid) or wood- (crosshatched) sourced biochars. The aluminum of the soils (right axis, (B)) is also plotted for Freeman (light grey) or Bernhill (dark grey) soils amended with KB- (circle) or wood- (triangle) sourced biochars (Trippe 2015). Amendment rates are represented as 0-4, which correspond to rates of $0 \%, 3 \%, 6 \%, 16 \%$, and $25 \%$ by volume for both biochars, $0 \%, 0.7 \%, 1.7 \%, 3.7 \%$, and $8.6 \%$ by mass for wood biochar, and $0 \%, 0.4 \%, 1.2 \%, 2.5 \%$, and $5.8 \%$ by mass for KB-sourced biochar.

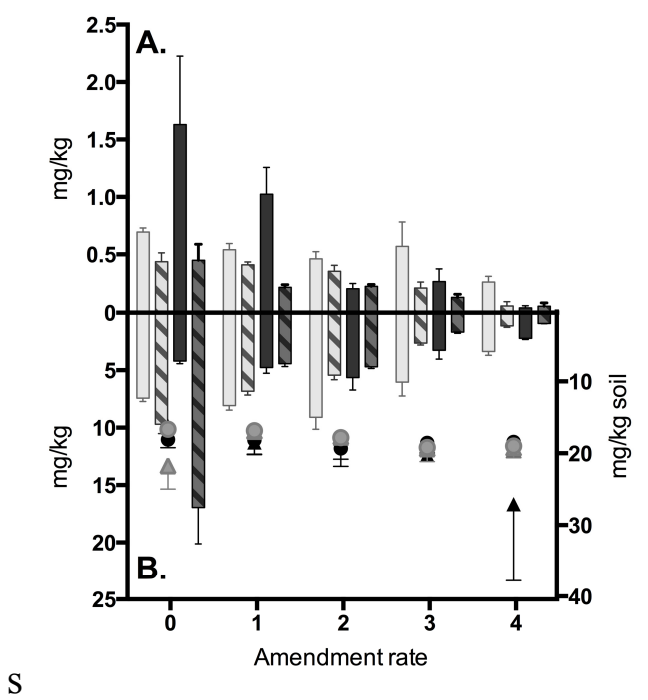

Figure 6. The nickel concentration of shoots (A) and roots (B) grown in Freeman (light grey) or Bernhill (dark grey) soils amended with KB- (solid) or wood- (crosshatched) sourced biochars. The nickel of the soils (right axis, (B)) is also plotted for Freeman (light grey) or Bernhill (dark grey) soils amended with KB- (circle) or wood(triangle) sourced biochars. Amendment rates are represented as $0-4$, which correspond to rates of $0,3,6,16$, and $25 \%$ by volume for both biochars, $0 \%, 0.7 \%, 1.7 \%, 3.7 \%$, and $8.6 \%$ by mass for wood biochar, and $0 \%, 0.4 \%, 1.2 \%, 2.5 \%$, and $5.8 \%$ by mass for KB-sourced biochar. 


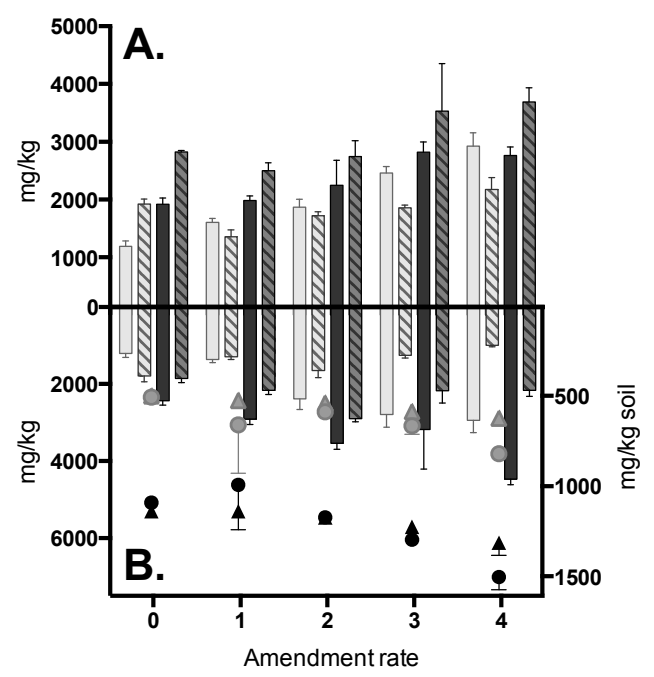

Figure 7. The phosphorus concentration of shoots $(\mathbf{A})$ and roots $(\mathbf{B})$ grown in Freeman (light grey) or Bernhill (dark grey) soils amended with KB- (solid) or wood- (crosshatched) sourced biochars. The phosphorus of the soils (right axis, (B)) is also plotted for Freeman (light grey) or Bernhill (dark grey) soils amended with KB- (circle) or wood- (triangle) sourced biochars (Trippe 2015). Amendment rates are represented as 0-4, which correspond to rates of $0 \%, 3 \%, 6 \%, 16 \%$, and $25 \%$ by volume for both biochars, $0 \%, 0.7 \%, 1.7 \%, 3.7 \%$, and $8.6 \%$ by mass for wood biochar, and $0 \%, 0.4 \%, 1.2 \%, 2.5 \%$, and $5.8 \%$ by mass for KB-sourced biochar.

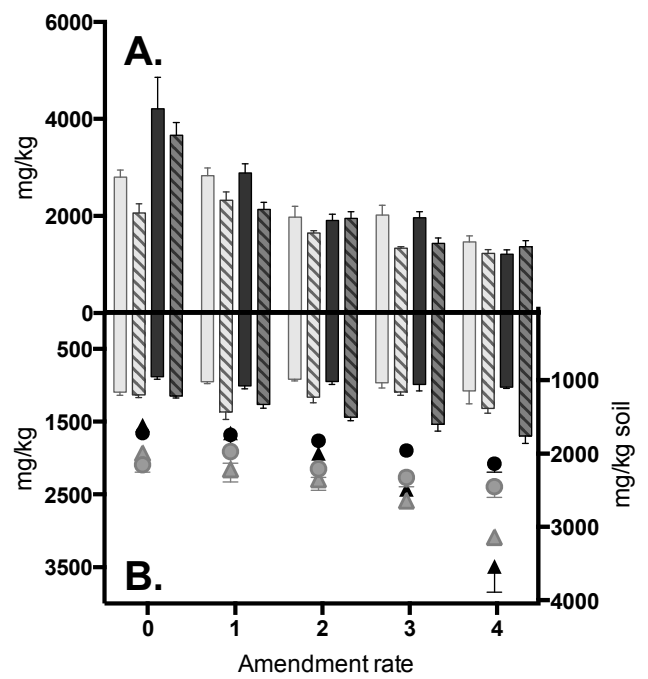

Figure 8. The calcium concentration of shoots (A) and roots (B) grown in Freeman (light grey) or Bernhill (dark grey) soils amended with KB- (solid) or wood- (crosshatched) sourced biochars. The calcium of the soils (right axis, (B)) is also plotted for Freeman (light grey) or Bernhill (dark grey) soils amended with KB- (circle) or wood- (triangle) sourced biochars (Trippe 2015). Amendment rates are represented as 0-4, which correspond to rates of $0 \%, 3 \%, 6 \%, 16 \%$, and $25 \%$ by volume for both biochars, $0 \%, 0.7 \%, 1.7 \%, 3.7 \%$, and $8.6 \%$ by mass for wood biochar, and $0 \%, 0.4 \%, 1.2 \%, 2.5 \%$, and $5.8 \%$ by mass for KB-sourced biochar. 
The general linear statistical model (Table 1) indicated that soil type was correlated with biochar-induced elemental changes in the plants. Elemental concentrations in plants grown in Bernhill soils were more likely to be impacted by biochar amendments. This correlation was especially notable in the elemental changes that occurred in the roots of plants grown in soil amended with wood-sourced biochar. However, the changes that we observed in elemental composition of the shoots did not seem to be strongly correlated to soil series.

\section{Discussion}

This study compared the effects of two biochars produced either by the gasification of wood or the gasification of $\mathrm{KB}$ seed screenings on the growth and nutrient status of wheat. A previous study characterized the effects of these same biochars on soil characteristics, including $\mathrm{pH}$ and fertility [12]. However, that study did not report the effects of these biochar amendments on plant growth. The objective of this study was to analyze these effects and to compare them to those observed in the soil study. Within this synthesis, our objective was to draw broader conclusions regarding the ability of the biochar to limit or promote the uptake of toxic metals or growth-promoting nutrients and tease out mechanisms that might lead to increased plant growth.

The previous [12] and the current study were conducted simultaneously in two similar soil series, Freeman and Bernhill. These specific soils were collected from agricultural fields where soil acidity $(\mathrm{pH}<5.0)$ limits crop productivity [13]. Prior to amendment, both the wood- and the KB-sourced biochars had similar $\mathrm{pH}$ values $(>10)$, at the highest amendment level, KB-sourced biochar increased the $\mathrm{pH}$ of the soil to $\sim 5.7$ while the wood-sourced biochar increased the $\mathrm{pH}$ even more $(\mathrm{pH}>6.4)$. Overall, our data indicate that the addition of either biochar to either soil increased plant biomass and improved their overall nutrient composition. Although the data indicate that these effects may be due to an increase in soil $\mathrm{pH}$, the addition of biochar also contributed plant nutrients that may have impacted plant growth.

We predicted that the main driver of increased plant growth in this study would be due to a $\mathrm{pH}$-mediated attenuation of $\mathrm{Al}$ toxicity in roots. Aluminum toxicity is thought to be a major factor in reduced plant growth in acidic soils [14]. Under experimental conditions, micromolar concentrations of Al severely inhibit root growth and alter the uptake of $\mathrm{Ca}$ and P [15]. Although we observed a noticeable reduction of $\mathrm{Al}$ concentrations in root tissue (Figure 2), our statistical analysis indicated that only the KB-sourced biochar significantly reduced the accumulation of Al in roots. This observation is interesting because only the highest amendment rate of KB-sourced biochar raised the pH (Figure 2A) beyond the threshold that significantly alters Al bioavailability [16]. This suggests that the KB-sourced biochar reduced $\mathrm{Al}$ uptake by another mechanism. Although Al is typically in solution below $\mathrm{pH}$ 5.5, once in solution it is able to complex with organic and inorganic compounds. A recent study demonstrated that trivalent $\mathrm{Al}$ complexes with rice-straw derived biochars [17], and that the presence of silicon increased surface complexation. Because grasses typically contain more silicon than wood, our observation that $\mathrm{KB}$-sourced biochar is more effective at lowering Al root concentrations than wood-sourced biochar may be attributable to fundamental biochar properties rather than a simple attenuation of $\mathrm{pH}$. 
The concentration of $\mathrm{Ni}$ in shoots and roots similarly declined. KB-sourced biochar was again more effective at reducing $\mathrm{Ni}$ uptake in the roots than wood-derived char, however, both biochars were effective at reducing $\mathrm{Ni}$ uptake in the shoots. These results mirrored those observed for Al, again indicating that declining concentrations of $\mathrm{Ni}$ are likely due to a combination of increasing $\mathrm{pH}$ and other soil or biochar properties. Previous studies have indicated that Ni bioavailability is dependent on soil organic matter [18] and on biochar particle size [19]. Overall, the combinatorial effects of an in increase in $\mathrm{pH}$ and intrinsic biochar properties likely led to most of the source-specific elemental changes we observed, including decreased Fe concentrations in roots grown with KB-sourced amendments and increased $\mathrm{Zn}$ concentrations in shoots grown in wood-sourced biochar.

In our study, root and shoot concentrations of potassium, phosphorus, and magnesium were enhanced with increasing quantities of biochar, regardless of the source material. These increases were likely due to the concentration of these elements in the biochar itself [12], and not to a change in $\mathrm{pH}$. Concentrations of $\mathrm{Ca}$ in shoots dramatically decreased (Figure 8A). This result was surprising because it has long been thought that $\mathrm{Al}$ elicits a phytotoxic response by disrupting $\mathrm{Ca}$ homeostasis [15]. Therefore, we predicted that alleviating Al toxicity would lead to an increase in root and shoot Ca concentrations. Although $\mathrm{Ca}$ levels decreased, even at the highest amendment rate, $\mathrm{Ca}$ concentrations were well above the critical deficiency threshold [20].

Sodium is not an essential nutrient for plant growth, and often causes phytotoxicity by disrupting potassium homeostasis [21]. Our results indicated that while $\mathrm{Na}$ concentrations stayed relatively constant in our amended soils, the concentration of $\mathrm{Na}$ in the roots dramatically decreased, suggesting that each biochar was able to sequester soil $\mathrm{Na}$.

An extensive meta-analysis of 371 biochar studies recently concluded that biochar amendments generally improve plant productivity, soil fertility, and nutrient content [3]. The results of the current study echo their conclusions, and reiterate that interactions between soil type and biochar properties are critical in determining whether biochar will have beneficial effects on plant growth. The final $\mathrm{pH}$ of the soil:biochar milieu will likely impact the effects of the amendment on plant growth, but it seems clear that additional soil and biochar characteristics influence whether plant productivity is impacted. The KB-sourced biochar used in this study has been fairly well-characterized in terms of its production [9], chemical characteristics [10], influence on soil fertility and nutrient content [12], and growth-promoting potential. Future studies that focus on the longevity of plant growth promoting properties and the economic impacts of biochar production will ultimately determine the consequences and potential for this char as an agricultural amendment prior to its widespread application.

\section{Experimental Section}

\subsection{Experimental}

Single plants of wheat (Triticum aestivum L. cv. Madsen, a commonly planted cultivar in the state of Washington, U.S.A.) were grown to a Feekes stage 5 (74 days) in $650 \mathrm{~cm}^{3}$ black plastic pots, containing either a Freeman or Bernhill soil with varying proportions of $\mathrm{KB}$ or wood biochar $(0 \%, 3 \%$, $6 \%, 16 \%$, and $25 \%$ by volume). Due to slight differences in of $\mathrm{KB}$ and wood biochar densities, the final mass concentration of $\mathrm{KB}$ biochar to soil was slightly different. In the soils amended with $\mathrm{KB}$ 
biochar, the highest amendment rate by mass was $5.8 \%$ and $8.6 \%$ with wood-based biochar. For simplicity, amendment rates in figures are represented as $0-4$, which correspond to rates of $0 \%, 3 \%$, $6 \%, 16 \%$, and $25 \%$ by volume for both biochars, $0 \%, 0.7 \%, 1.7 \%, 3.7 \%$, and $8.6 \%$ by mass for wood biochar, and $0 \%, 0.4 \%, 1.2 \%, 2.5 \%$, and $5.8 \%$ by mass for KB-sourced biochar. Plants were grown in a greenhouse at Corvallis, OR, U.S.A. with supplemental lighting using high-pressure sodium lamps, with an average quantum flux density of $150 \mu \mathrm{E} \mathrm{m}^{-2} \mathrm{~s}^{-1}$ and extended day length to $16 \mathrm{~h}$. Average daily maximum and minimum temperature was 21.1 and $15.6{ }^{\circ} \mathrm{C}$, respectively. Plants were watered twice a week for $74 \mathrm{~d}$. During the duration of the study, no supplemental nutrients were added to the treatments other than what was present initially in the soil and biochar.

The two biochars used in this study were Class 2 biochars as defined by the International Biochar Initiative [22]. The KB biochar was produced using a small-scale gasification unit located on a farm near Rockford, WA, U.S.A. [9]. The stainless steel reactor of $0.45 \mathrm{~m}^{3}$ was air-blown at a rate of 3 to $3.5 \mathrm{~m}^{3} \mathrm{~min}^{-1}$ and operated at temperatures ranging from 650 to $750{ }^{\circ} \mathrm{C}$ at a feed rate of 60 to $80 \mathrm{~kg} \mathrm{~h}^{-1}$. The KB source material was obtained during a post-harvest seed cleaning procedure and consisted largely of small Kentucky bluegrass straw components, immature seeds, and remnant seed coats. The moisture content of the KB was $14 \%$ and the predominant particles in the feedstock were less than $5 \mathrm{~cm}$ in length. An extensive characterization of KB biochar was previously reported by Griffith et al. [10]. The second biochar was produced from gasification of chipped residues of a Douglas-fir (Pseudotsuga menziesii (Mirb.) Franco), Ponderosa pine (Pinus ponderosa C. Lawson), white fir (Abies concolor (Gord. \& Glend.) Lindl. ex Hildebr.), sugar pine (Pinus lambertiana Douglas), and incense cedar (Calocedrus decurrens (Torr.) Florin) harvest. The wood biochar was produced using a small-scale down-draft gasification unit that was air-blown to produce gas at about $170 \mathrm{~m}^{2} \mathrm{~h}^{-1}$ and operated at maximum char temperatures ranging from 1100 to $1400{ }^{\circ} \mathrm{C}$ at a feed rate of about $70 \mathrm{~kg} \mathrm{~h}^{-1}$. The moisture content of the woody source material was $9 \%$ to $15 \%$. Elemental and proximate analyses of these biochars were previously published $[10,12]$.

The two cultivated farm soils used in this study were obtained near Rockford, WA, U.S.A. from two different fields. The Freeman soil was collected at Lat. 47.506539 N, Long. $-117.096256 \mathrm{~W}$ and the Bernhill soil at Lat. 47.51686 N, Long. -117.068213 W. The Freeman soil series is an Aquandic Palexeralf [23] with very deep, moderately well drained soil formed in loess with a minor amount of volcanic ash mixed in the surface. Freeman soils are found on undulating to rolling loess hills on slopes of $0 \%$ to $30 \%$. The Bernhill series consists of very deep, well-drained soils formed in glacial till with a component of loess and volcanic ash at the surface. Bernhill soils are Vitrandic Haploxeralfs [23] on glaciated foothills and glaciolacustrine influenced ground moraines with slopes of $0 \%$ to $65 \%$. The two soils were selected in an area predominated by Kentucky bluegrass seed and wheat production and a farming area with historically acidic soils and other nutrient deficiencies [13].

\subsection{Plant Analysis}

After $74 \mathrm{~d}$ from the time of planting, wheat shoots and roots were separated, dried at $40{ }^{\circ} \mathrm{C}$ for $24 \mathrm{~h}$, dry mass recorded, and then ground using a Cyclotec 1093 Sample Mill (Tecator, Hoganas, Sweden) fitted with $1 \mathrm{~mm}^{2}$ screen. Roots were quickly rinsed to remove all adhering soil prior to drying. Plant material was dried at $40{ }^{\circ} \mathrm{C}$, then ground and passed through a 2-mm sieve. We analyzed the total 
concentrations in ground shoot and root tissue $\mathrm{Ca}, \mathrm{Cu}, \mathrm{Fe}, \mathrm{K}, \mathrm{Mg}, \mathrm{Mn}, \mathrm{Na}, \mathrm{P}, \mathrm{S}$, and $\mathrm{Zn}$, essential plant macro- and micronutrients, and $\mathrm{Al}, \mathrm{As}, \mathrm{Cd}, \mathrm{Na}$, and $\mathrm{Ni}$, which are potentially toxic. These analyses were performed as described in Milestone Digestion Application Report \#03-001. This procedure involved an initial sample digestion in a Milestone Ethos D microwave (Milestone Inc., Shelton, CT) with $\mathrm{HNO}_{3}$ and $\mathrm{HCl}$, followed by inductively coupled plasma atomic emission spectrometry (Perkin-Elmer Optima 46300 DV ICP-OES) analysis. Total $\mathrm{C}$ and $\mathrm{N}$ were quantified using a $\mathrm{C} / \mathrm{N}$ combustion analyzer (LECO TruSpec, St. Joseph, MI).

\subsection{Soil Analysis}

The effect of biochar additions on $\mathrm{pH}$ and on soil concentrations of $\mathrm{Al}, \mathrm{Ca}, \mathrm{K}, \mathrm{Mg}$, and $\mathrm{P}$ were previously published [12], but were collected during the greenhouse study described above. The concentrations of $\mathrm{Ni}, \mathrm{Fe}, \mathrm{Na}$, and $\mathrm{Zn}$ were also measured during that study, however the concentrations of these elements were not reported. The soil concentrations of each of these elements are plotted here to provide context.

\subsection{Statistical Analysis}

This study used a completely randomized block design of five blocks with treatments randomized within each block and block identities were retained in the greenhouse through the duration of the experiment. Blocks were entered in the model as random effects and soil type, biochar type, and biochar concentration were treated as fixed effects. Data were statistically analyzed using the General Linear Model $(\mathrm{A}+\mathrm{B}+\mathrm{C}+\mathrm{D}+\mathrm{BC}+\mathrm{BD}+\mathrm{CD}+\mathrm{BCD})$ function in the $\mathrm{R}$ basic statistics package [24] that included planned comparisons testing whether the linear, quadratic, cubic and quartic components were significant. The results were analyzed as linear models with nested fixed effects, where biochar amendment rate was nested within biochar type. The fixed effects were biochar type, soil type, amendment rate within biochar type, biochar type $\times$ soil type interaction, and biochar concentration $\times$ soil type interaction within biochar type.

\section{Conclusion}

This study compared the ability of biochars produced by the gasification of readily available local feedstocks to impact the growth and nutrient status of wheat. To quantify these effects we conducted a greenhouse study that evaluated these parameters in wheat grown in highly weathered agricultural soils amended with either KB or wood-sourced biochar. Our studies indicated that biochar amended soils promoted the growth of wheat. Our elemental analysis indicated that this growth was likely attributed to an attenuation of metal toxicity and an increase in $\mathrm{pH}$. However, the ability of the biochars to raise soil $\mathrm{pH}$ was not solely responsible for the change in metal accumulation in the roots and the shoots, and that other intrinsic biochar properties also contributed to metal sequestration. Likewise, each of these biochars provided plants with essential plant nutrients that are typically limited in these agricultural alfisols. 


\section{Acknowledgments}

We thank Jennifer Young for her technical assistance, David Gady and Tom Jobson for the production of the biochars, and Mark Johnson for his insightful comments. Reference to trade names does not imply endorsement by the U.S. Government. USDA is an equal opportunity provider and employer. Mention of trade names or commercial products in this publication is solely for the purpose of providing specific information and does not imply recommendation or endorsement by the U.S. Department of Agriculture.

\section{Conflict of Interest}

The authors declare no conflict of interest.

\section{References}

1. Banowetz, G.M.; Boateng, A.; Steiner, J.J.; Griffith, S.M.; Sethi, V.; El-Nashaar, H. Assessment of straw biomass feedstock resources in the Pacific Northwest. Biomass Bioenergy 2008, 32, 629-634. doi:10.1016/j.biombioe.2007.12.014.

2. Mueller-Warrant, G.W.; Banowetz, G.M.; Whittaker, G.W. Geospatial identification of optimal straw-to-energy conversion sites in the Pacific Northwest. Biofuels Bioprod. Biorefining 2010, 4 , 385-407.

3. Biederman, L.A.; Stanley Harpole, W. Biochar and its effects on plant productivity and nutrient cycling: A meta-analysis. GCB Bioenergy 2013, 5, 202-214, doi:10.1111/gcbb.12037.

4. Novak, J.M.; Busscher, W.J.; Laird, D.L.; Ahmedna, M.; Watts, D.W.; Niandou, M.A.S. Impact of Biochar Amendment on Fertility of a Southeastern Coastal Plain Soil. Soil Sci. 2009, 174, 105-112, doi:10.1097/SS.0b013e3181981d9a.

5. Lehmann, J.; Joseph, S. Biochar for Environmental Management: Science and Technology; Earthscan: Sterling, VA, USA, 2012; pp. 127-146.

6. Maestrini, B.; Herrmann, A.M.; Nannipieri, P.; Schmidt, M.W.I.; Abiven, S. Ryegrass-derived pyrogenic organic matter changes organic carbon and nitrogen mineralization in a temperate forest soil. Soil Biol. Biochem. 2014, 69, 291-301, doi:10.1016/j.soilbio.2013.11.013.

7. Rogovska, N.; Laird, D.; Cruse, R.M.; Trabue, S.; Heaton, E. Germination tests for assessing biochar quality. J. Environ. Qual. 2012, 41, 1014-1022.

8. Mozaffari, M.; Russelle, M.P.; Rosen, C.J.; Nater, E.A. Nutrient supply and neutralizing value of alfalfa stem gasification ash. Soil Sci. Soc. Am. J. 2002, 66, 171-178.

9. Banowetz, G.M.; El-Nashaar, H.; Steiner, J.J.; Gady, D. Non-Densified Biomass Gasification Method and Apparatus. US20110220846 A1, 15 September 2011.

10. Griffith, S.M.; Banowetz, G.M.; Gady, D. Chemical characterization of chars developed from thermochemical treatment of Kentucky bluegrass seed screenings. Chemosphere 2013, 92, 1275-1279, doi:10.1016/j.chemosphere.2013.02.002.

11. Mozaffari, M.; Rosen, C.J.; Russelle, M.P.; Nater, E.A. Chemical characterization of ash from gasification of alfalfa stems: Implications for ash management. J. Environ. Qual. 2000, 29, 963-972. 
12. Trippe, K.M.; Griffith, S.M.; Banowetz, G.M.; Whitaker, G.W. Changes in Soil Chemistry following Wood and Grass Biochar Amendments to an Acidic Agricultural Production Soil. Agron. J. 2015, doi:10.2134/agronj14.0593.

13. Koenig, R.; Schroeder, K.; Carter, A.; Pumphery, M.; Paulitz, T.; Campbell, K.; Huggins, D. Soil acidity and aluminum toxicity in the Palouse Region of the Pacific Northwest. Available online: http://cru.cahe.wsu.edu/CEPublications/FS050E/FS050E.pdf (accessed on 15 July 2015).

14. Ryan, P.R.; Kochian, L.V. Interaction between aluminum toxicity and calcium uptake at the root apex in near-isogenic lines of wheat (Triticum aestivum L.) differing in aluminum tolerance. Plant Physiol. 1993, 102, 975-982.

15. Kochian, L.V. Cellular mechanisms of aluminum toxicity and resistance in plants. Annu. Rev. Plant Biol. 1995, 46, 237-260.

16. Sparling, D.W.; Lowe, T.P. Environmental Hazards of Aluminum to Plants, Invertebrates, Fish, and Wildlife; Springer: New York, NY, USA, 1996; pp. 1-127.

17. Qian, L.; Chen, B. Interactions of aluminum with biochars and oxidized biochars: Implications for the biochar aging process. J. Agric. Food Chem. 2014, 62, 373-380, doi:10.1021/jf404624h.

18. Weng, L.P.; Wolthoorn, A.; Lexmond, T.M.; Temminghoff, E.J.M.; van Riemsdijk, W.H. Understanding the Effects of Soil Characteristics on Phytotoxicity and Bioavailability of Nickel Using Speciation Models. Environ. Sci. Technol. 2004, 38, 156-162, doi:10.1021/es030053r.

19. Rees, F.; Simonnot, M.O.; Morel, J.L. Short-term effects of biochar on soil heavy metal mobility are controlled by intra-particle diffusion and soil pH increase. Eur. J. Soil Sci. 2014, 65, 149-161, doi:10.1111/ejss.12107.

20. Genc, Y.; Tester, M.; McDonald, G.K. Calcium requirement of wheat in saline and non-saline conditions. Plant Soil 2010, 327, 331-345, doi:10.1007/s11104-009-0057-3.

21. Kronzucker, H.J.; Coskun, D.; Schulze, L.M.; Wong, J.R.; Britto, D.T. Sodium as nutrient and toxicant. Plant Soil 2013, 369, 1-23, doi:10.1007/s11104-013-1801-2.

22. Initiative, I.B. Standardized product definition and product testing guidelines for biochar that is used in soil. IBI biochar Stand. 2012. Availiable online: http://www.biocharinternational.org/sites/default/files/IBI_Biochar_Standards_V2\%200_final_2014.pdf (accessed on 14 August 2015).

23. USDA-NRCS. Soil Series of Spokane County. Official Soil Series Descriptions; USDA-NRCS, United States Department of Agriculture: Lincoln, NE, USA, 2006. Available online: http://www. nrcs.usda.gov/Internet/FSE_MANUSCRIPTS/washington/spokaneWA1968/spokaneWA1968.pdf. (accessed on 14 August 2015).

24. R Development Core Team. R: A Language and Environment for Statistical Computing; R Foundation for Statistical Computing: Vienna, Austria, 2014.

(C) 2015 by the authors; licensee MDPI, Basel, Switzerland. This article is an open access article distributed under the terms and conditions of the Creative Commons Attribution license (http://creativecommons.org/licenses/by/4.0/). 